\title{
Advancements in the Neuroimaging of the Spinal Cord
}

\author{
M. Perovitch, M.D. \\ Professor of Neuroradiology, The University of Connecticut School of Medicine \\ and Health Center, Farmington, Connecticut 06032, U.S.A.
}

\begin{abstract}
Summary
$A$ review is presented concerning the recent developments in neuroimaging techniques of the spinal cord. The present role of computed tomography with Metrizamide myelography, digital subtraction angiography, positron emission tomography, and magnetic resonance imaging is specifically analysed.

Key words: Advancements; Spinal cord neuroimaging.
\end{abstract}

\section{Introduction}

For about 5 decades myelography, either with positive or negative contrast media, had been the main neuroradiological tool for the exploration of the spinal cord (Perovitch, 1981). It was an uncomfortable procedure for a paraplegic, occasionally associated with complications due to intrathecal use of iodinate contrast media, or to myelographic techniques (Perovitch, 1981). Furthermore, myelography required hospitalisation in most cases. Since 1970 spinal cord angiography has been used to supplement myelography. Although this diagnostic modality proved to be valuable for the evaluation of the cord's blood circulation, it was, in the beginning, a tedious experience for the patient, linked to risks related to the toxicity of contrast agents and to catheterisation of small spinal cord arteries with catheters of a relatively large diameter (Perovitch, 1981).

In the recent past, advanced neuroimaging techniques were introduced resulting from new concepts and developments in computer science and applied mathematics. Four of these techniques, that have evolved or have been considerably improved, are having a great impact on the neuroradiological examination of the spinal cord. They are: Computed tomography (CT) with less toxic water-soluble contrast media; Digital subtraction angiography (DSA) with smaller size catheters; Positron emission tomography (PET); and Magnetic resonance imaging (MRI) with Hydrogen $\left({ }^{1} \mathrm{H}\right)$. Their introduction into clinical practice has upgraded and broadened neuroradiological diagnostic capabilities, 
and also rendered the examination of the spinal cord more tolerable and less hazardous to the paraplegic.

\section{Computed tomography}

Through several 'generations' CT has reached a high level of technical sophistication which has enhanced its diagnostic capabilities by increasing the contrast discrimination, and by shortening scanning, and reconstruction times. The diagnostic significance of CT in the evaluation of the spine has considerably increased since the high-resolution technique has improved the detection of bony details. However, CT failed to achieve a clear distinction between the spinal cord and the surrounding anatomical elements. Therefore, the intrathecal introduction of water-soluble contrast agents became essential to delineate the spinal cord in CT images. At present, CT Metrizamide Myelography (CTMM) has been used for the evaluation of various types of spinal pathology, congenital as well as acquired. The refinement of water-soluble contrast media such as Metrizamide (or Amipaque, etc.) has significantly improved the clinical utility of high-resolution CT in regard to spinal cord assessment (Perovitch, 1985). However, CTMM possesses combined disadvantages of both CT and myelography: invasiveness, radiation, and intrathecal application of contrast media.

Concerning the CT evaluation of the spine we can expect further reduction of the scanning time and of slice-thickness, as well as further upgrading of simultaneous multiplanar imaging (Perovitch, 1985).

\section{Digital subtraction angiography}

Introduced in the late 70s, DSA has been used only recently for spinal cord angiography. It has reduced the procedure time, and also the radiation dose. The new catheters, such as the 4-F, 3-F, and the microcatheters, have decreased the hazards linked to the catheterisation of small arteries (Perovitch et al., 1986).

The possibility of introducing a larger image field and the biplane arrangement for imaging will certainly enhance a broader application of intra-arterial spinal cord DSA. Furthermore, a $1024 \times 1024$ matrix could give this modality a spatial resolution equivalent to the conventional spinal cord film-screen angiography (Perovitch, 1986-I).

\section{Positron emission tomography}

Following a long laboratory stage, PET has been recently moved into clinical setting. In the first period of its clinical application, PET was successfully used to measure blood flow, and later of amino-acid, sugar, etc., as well as of the receptor concentration in the body. PET's ability to localise neurotransmitter receptors in the brain is expected to open up new diagnostic possibilities which may influence our views regarding some types of central nervous system disorders (Parkinson's disease, Alzheimer's disease, myasthenia gravis, etc.) and modify their clinical treatment (Perovitch, 1985).

Experience with the application of PET in spinal cord disorders, at present, is limited. However, it is reasonable to expect that this modality may prove to be a useful tool for the evaluation of spinal cord pathology.

The use of PET is, of course, associated with the risks linked to radiation (Perovitch, 1985). The future will show if PET's potentials to study chemical 


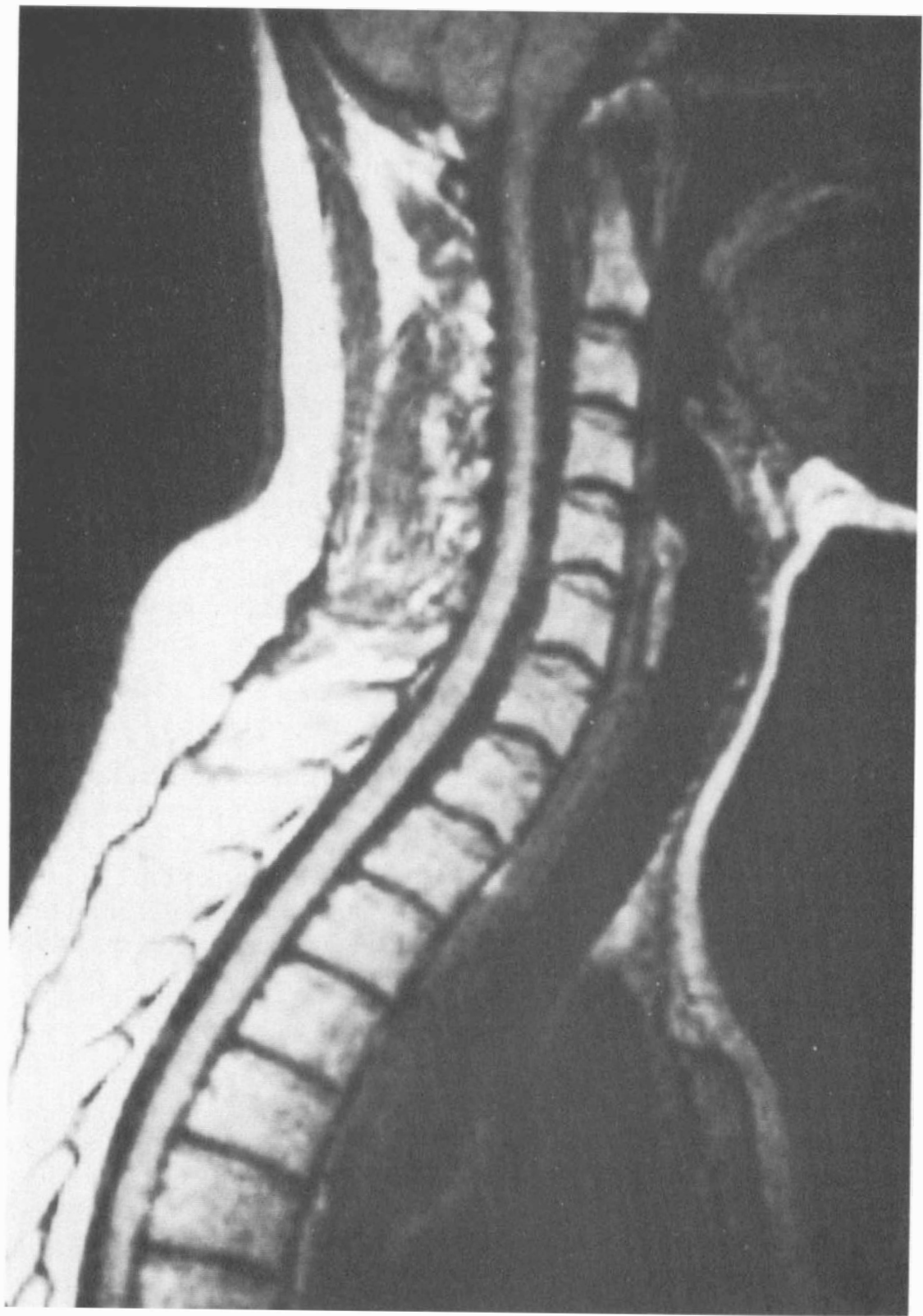

Figure 1 The magnetic resonance image of the cervical spinal cord. The spinal cord is clearly outlined without the injection of contrast media. 


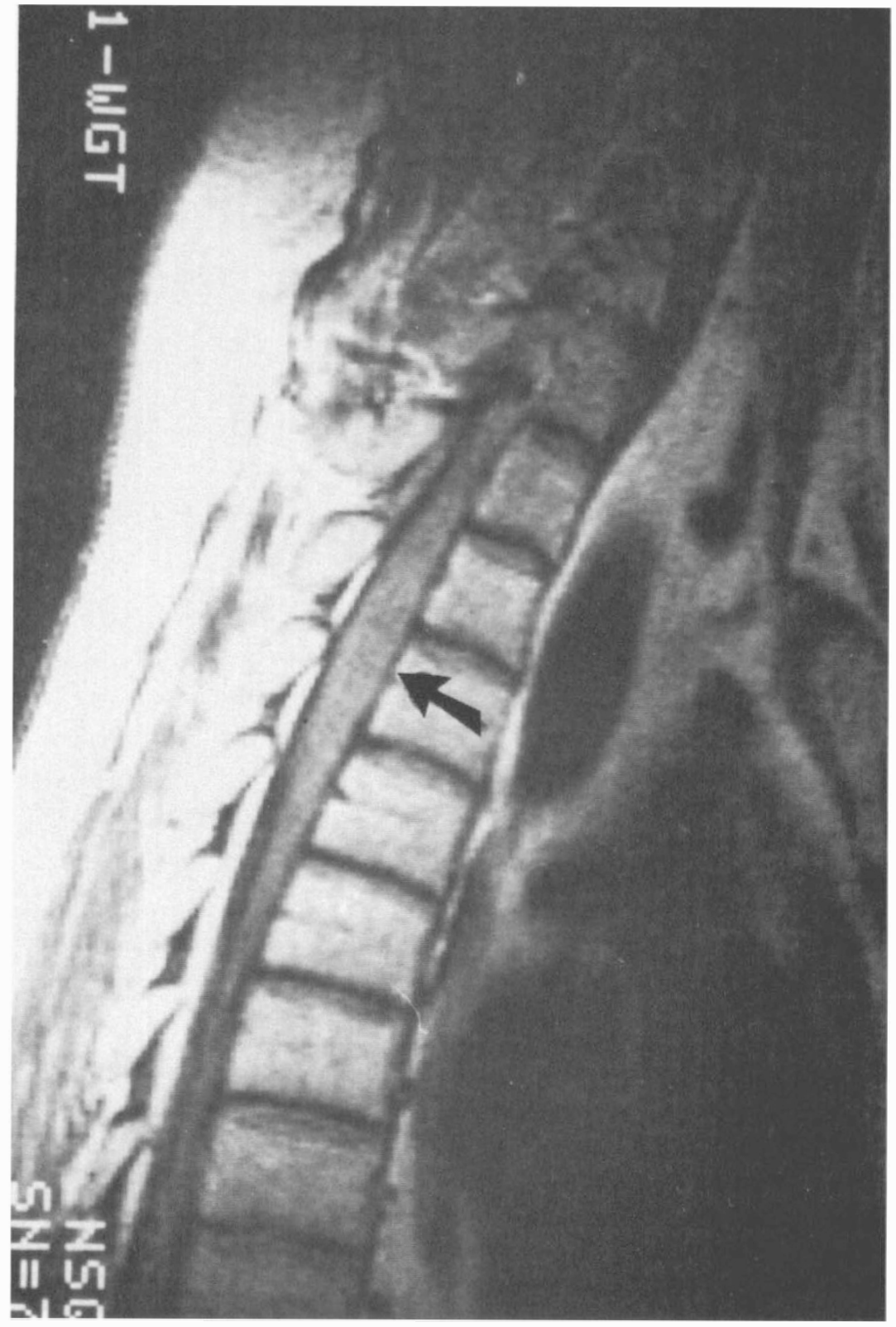

Figure 2 An enlargement of the spinal cord with bright signal in the $T_{1}$ image in the thoracic region is demonstrated by means of magnetic resonance. It represents an intramedullary glioma (arrow). 


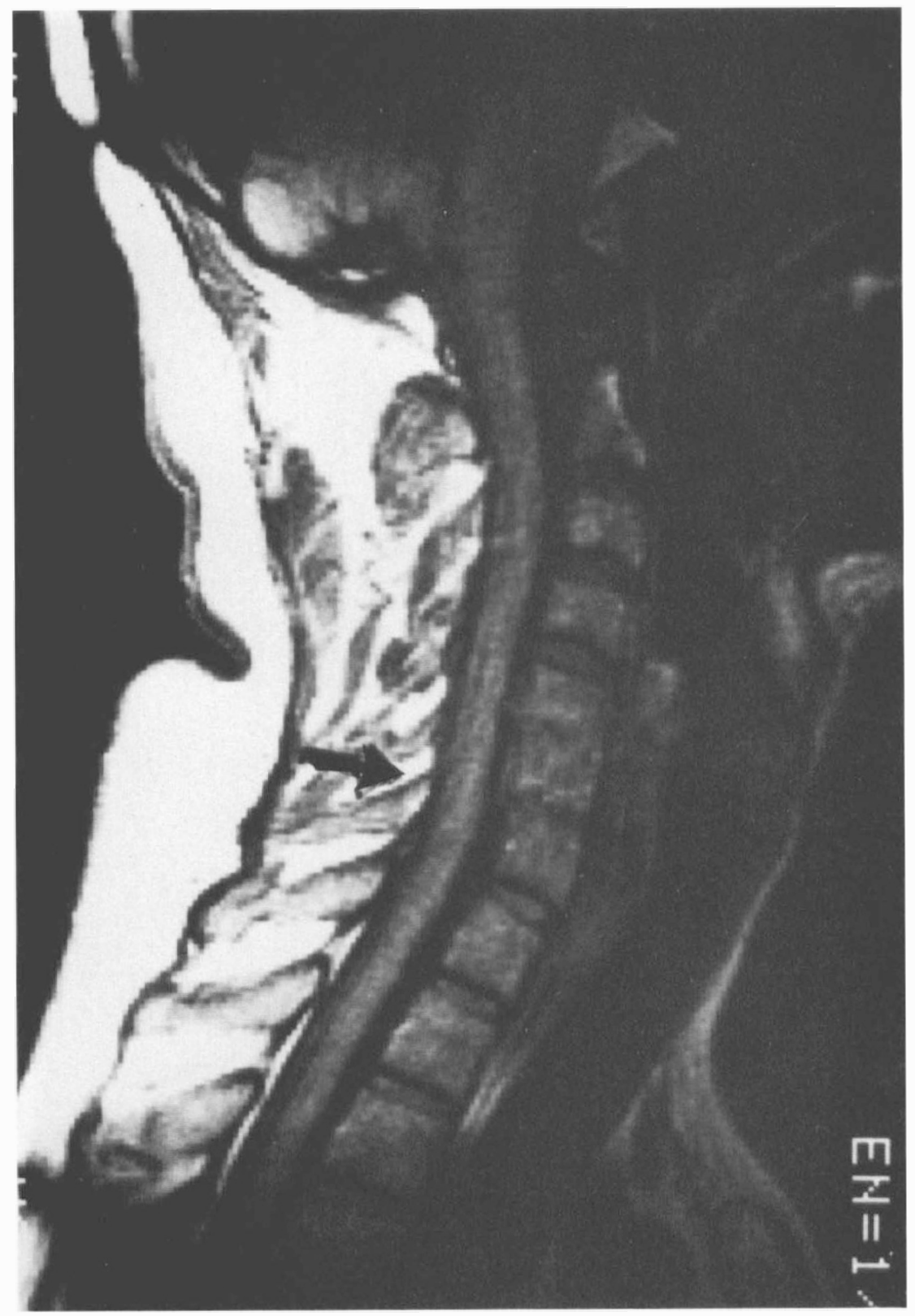

Figure 3 Magnetic resonance image of the compressed cervical spinal cord by a herniated disc at $\mathrm{C}_{4-5}$ level (arrow). 
defects and the expected benefits of such studies will outweigh the risks of ionising radiation.

\section{Magnetic resonance imaging with hydrogen $\left({ }^{1} \mathrm{H}\right)$}

In the last 2 years MRI has been used more extensively for spinal cord examination. It has demonstrated distinct advantages over other neuroimaging modalities. MRI provides, for the first time, simultaneous multiplanar imaging of the entire length of the spinal cord and cervicomedullary junction without intrathecal administration of contrast agents or ionising radiation. MRI can be achieved without moving the patient, and can be repeated on an outpatient basis. Furthermore, MRI, when available, has been replacing other neuroimaging techniques for the evaluation of the spinal cord injury in shock-trauma services (Figs 1, 2 and 3).

In addition to the proton MRI of the spinal cord there is a possibility to obtain images of the distribution of other nuclei, such as Sodium $\left({ }^{23} \mathrm{Na}\right)$ or Phosphorus $\left({ }^{31} \mathrm{P}\right)$, that may have greater diagnostic values than Hydrogen. This means that in future we could explore, under clinical conditions, biochemical processes that occur in the spinal cord under normal and pathological conditions (Perovitch, 1986-II).

Some existing limitations of MRI of the spinal cord, such as large slicethickness, long imaging time, lack of signal from the cortical bone, optimisation of pulse sequences, presence of ferro-magnetic life-support devices, shall probably be resolved in the near future through further advances in MRI technology.

\section{Conclusion}

The rapid recent proliferation of highly sophisticated technology has changed previous approaches to the neuroradiological evaluation of the spinal cord. One can expect further expansion and improvement of neuroimaging modalities that will open up entirely new ways for the assessment of spinal cord pathology, and probably considerably influence present concepts regarding spinal cord disorders that cause neurological disabilities.

\section{References}

Perovitch M, OtTESEN O 1986 Advancements in the DSA of the brachiocephalic blood vessels. In: Reisner T, Binder H, Deisenhammer E (eds) Advances in Neuroimaging. Verlag der Wiener Medizinischen Akademie, Wien, pp 149-154

Perovitch M 1986 (I) Application of digital subtraction angiography in neurological disorders. In: Poeck K, Freund H-J, Gänshirt H (eds) Neurology. Springer-Verlag, Berlin, Heidelberg, New York, Tokyo, pp 453-462.

Perovitch M 1986 (II) Potential application of magnetic resonance spectroscopy in the clinical setting. In: Burrell CD, Strans FL (eds). Second Colloquium in Biological Sciences, Annals of the New York Academy of Sciences New York 463:337-338

Perovitch M 1985 Neuroradiological evaluation of headache. In: Pfaffenrath V, Lundberg PO, SJaAnstad O (eds), Updating in Headache. Springer-Verlag, Berlin, Heidelberg, New York, pp 76-86

Perovitch M 1981 Radiological Evaluation of the Spinal Cord, Vol. I, Perovitch M (ed). CRC Press, Boca Raton, Florida

Perovitch M 1981 Complication related to positive contrast myelography. In: Perovitch M Radiological Evaluation of the Spinal Cord, Vol. I, (ed). CRC Press, Boca Raton, Florida, pp 79-92

Perovitch M 1981 Spinal cord angiography. In: Perovitch M (ed). Radiological Evaluation of the Spinal Cord, Vol. II, CRC Press, Boca Raton, Florida, pp 67-98 